\title{
Metacercárias livres (Digenea: Diplostomidae) em Rhinella fernandezae (Anura: Bufonidae) no Sul do Brasil
}

\author{
Free metacercariae (Digenea, Diplostomidae) in Rhinella fernandezae (Anura: Bufonidae) \\ in southern Brazil
}

Viviane Gularte Tavares dos Santos ${ }^{\mathrm{I}}$ Suzana Bencke Amato ${ }^{\mathrm{II}}$

\section{- NOTA-}

RESUMO

Metacercárias livres de uma espécie não determinada de trematódeo digenético (Diplostomidae) foram encontradas nos rins de anuros da espécie Rhinella fernandezae coletados no Município de Imbé, Litoral Norte do Rio Grande do Sul, Brasil. Em uma amostra de 90 anuros, as metacercárias apresentaram prevalência de $3,3 \%$ e intensidade de infecção de 8,7 helmintos/hospedeiro. Este é o primeiro registro de metacercárias livres de diplostomídeos em anuros da região Sul do Brasil e do Estado do Rio Grande do Sul.

Palavras-chave: Rhinella, sapo, hospedeiro intermediário, trematódeo digenético, rim.

\section{ABSTRACT}

Free metacercariae of an undetermined species of digenetic (Diplostomidae) were found over in the kidneys of anurans of the species Rhinella fernandezae collected in the in the municipality of Imbé, on the northern coast of Rio Grande do Sul, in southern Brazil. In a sample of 90 anurans, the prevalence of free metacercariae was 3,3, and the mean intensity of infection was 8,7 helminths/host. This is the first record of free metacercariae in anurans from Southern Brazil and from the State of Rio Grande do Sul.

Key words: Rhinella, toad, intermediate host, digenetic trematode, kidney.

Os sapinhos de jardim, Rhinella fernandezae (Gallardo, 1957), pertencem à família Bufonidae, que tem ampla distribuição geográfica, compreendendo todas as regiões temperadas e neotropicais, exceto Austrália (KWET \& DIBERNARDO, 1999). Rhinella fernandezae ocorre na Argentina, no Paraguai, no Uruguai e no Rio Grande do Sul (IUCN, 2008). Essa espécie costuma viver em tocas que constrói com auxílio das patas traseiras (ACHAVAL \& OLMOS, 2003). Segundo DURÉ \& KEHR (1999), R. fernandezae apresenta uma dieta diversificada (insetos, aracnídeos, crustáceos), apresentando preferência por formigas.

Os diplostomídeos pertencem à superfamília Diplostomoidea Poirier, 1886, são trematódeos digenéticos que, quando adultos, parasitam aves e mamíferos, e no estágio de metacercárias parasitam peixes e anfíbios (YAMAGUTI, 1971). A superfamília Diplostomoidea compreende indivíduos distintamente diferentes de outros grupos de trematódeos digenéticos, por possuir o órgão tribocítico, uma estrutura bilobada com função de adesão e digestão (NIEWIADOMSKA, 2002).

Neste relato, registra-se, pela primeira vez no Brasil, $\boldsymbol{R}$. fernandezae como segundo hospedeiro intermediário de digenéticos diplostomídeos, sendo o primeiro registro de metacercárias livres desses digenéticos em anuros no Sul do Brasil e no Estado do Rio Grande do Sul (RS).

Foram coletados 90 anuros, entre agosto de 2006 e abril de 2007, com autorização do Instituto Brasileiro do Meio Ambiente (IBAMA, licença nº 026/

IPrograma de Pós-graduação em Biologia Animal (PPG-BAN), Universidade Federal do Rio Grande do Sul (UFRGS), 91501-970, Porto Alegre, RS, Brasil. E-mail: vitagu_imbe@hotmail.com. Autor para correspondência.

ID Departamento de Zoologia e PPG-BAN, UFRGS, Porto Alegre, RS, Brasil. 
2006), no Município de Imbé (2958’31’S, 5007’41”W), localizado na região costeira do Rio Grande do Sul, Brasil. Os anuros foram capturados manualmente com auxílio de pá de jardim, transportados ao laboratório em recipientes plásticos e mantidos no laboratório em terrário contendo substrato do local de coleta. Os sapos foram sacrificados com lidocaína Geyer 2\% (Di Bernardo, comunicação pessoal) passada sobre o ventre do animal e absorvida pela pele. Posteriormente, os sapos foram necropsiados, sendo esse procedimento realizado no Laboratório de Helmintologia, Departamento de Zoologia da Universidade Federal do Rio Grande do Sul. Os procedimentos de necropsia, coleta e processamento foram feitos de acordo com AMATO \& AMATO (2009). Os trematódeos digenéticos foram coletados e colocados em solução salina fisiológica $0,65 \%$. Logo foram fixados em A.F.A (etanol $70^{\circ} \mathrm{GL}$ - 93 partes; formalina $37 \%$ - cinco partes; ácido acético glacial- duas partes), sob leve compressão, corados em hematoxilina de Delafield (HUMASON, 1972), clarificados em óleo de cedro e montados em bálsamo do Canadá. As medidas são apresentadas em micrometros $(\mu \mathrm{m})$, caso contrário a unidade foi indicada; a amplitude de variação de cada caractere, é seguida, entre parênteses, pela média, pelo desvio padrão e pelo número de espécimes medidos. Todos os hospedeiros foram depositados no Museu de Ciências e Tecnologia da Pontifícia Universidade Católica do Rio Grande do Sul (PUCRS), em Porto Alegre, RS.

Os digenéticos encontrados nos rins dos anuros foram identificados como metacercárias livres (não encistadas). Onze espécimes foram montados in toto e apresentavam corpo oval ou elíptico, quando não comprimido. A porção posterior não é desenvolvida; com 250 a $380(319 ; 11 ; 47,56)$ de comprimento total e 150 a $260 \mathrm{~mm}(195 ; 11 ; 31,45)$ de largura. A ventosa oral subterminal (Figura 1) apresentava 30 a $50(41,05 ; 11 ; 6,13)$ de comprimento e 25 a $40(34 ; 11 ; 5,31)$ de largura. Os animais não apresentam ventosas acessórias. No entanto, apresentavam faringe, com 25 a $45(46,5 ; 10 ; 6,57)$ de comprimento e 23 a $40(26,9 ; 10 ; 4,84)$ de largura, e esôfago. Apresentavam também acetábulo redondo (Figura 1), na linha mediana do corpo, com 18 a 40 $(28,63 ; 10 ; 7,74)$ de comprimento e com 26 a $43(36,60$; $10 ; 5,84$ ) de largura, e órgão tribocítico (Figura 1) com 91 a $153(124,5 ; 10 ; 23,09)$ de comprimento e 31 a 75 $(47,7 ; 10 ; 12,35)$ de largura, pós-acetabular, elíptico, com uma fenda longitudinal. Além disso, apresentavam vesícula excretora em forma de $\mathrm{V}$; bem visível quando cheia. As metacercárias apresentaram 3,33\% de prevalência e 8,66 helmintos/hospedeiro de intensidade média de infecção, sendo esses valores considerados baixos quando comparados à prevalência de 52,6\% de metacercárias livres de diplostomídeos encontradas em Loricariichtys anus no Rio Jacuí, RS (AMATO et al. 2001). Espécimes representativos foram depositados na Coleção Helmintológica do Instituto Oswaldo Cruz (CHIOC no 37203) e na Coleção Helmintológica do Departamento de Zoologia, da Universidade Federal do Rio Grande do Sul (UFRGS) (CHDZ-UFRGS nº JFA 2572-8-2).

As metacercárias livres foram identificadas como pertecentes à superfamília Diplostomoidea, de acordo com a chave de GIBSON et al. (2002), e apresentando órgão tribocítico característico das espécies pertencentes a essa superfamília. Essa superfamília inclui seis famílias: Brauninidae Bosma, 1931; Bolbocephalodidae Strand, 1935; Cyathocotylidae Mühling, 1898; Strigeidae Railliet, 1919; Diplostomidae Poirier, 1886 e Proterodiplostomidae Dubois, 1936 (NIEWIADOMSKA, 2002).

De acordo com NIEWIADOMSKA (2002), em muitas espécies das famílias Cyathocotylidae, Strigeidae e Diplostomidae, os ciclos de vida e a morfologia das cercárias e metacercárias são bem conhecidos. A morfologia das metacercárias é semelhante entre espécies de gêneros relacionados, diferindo entretanto em relação ao sistema excretor, o

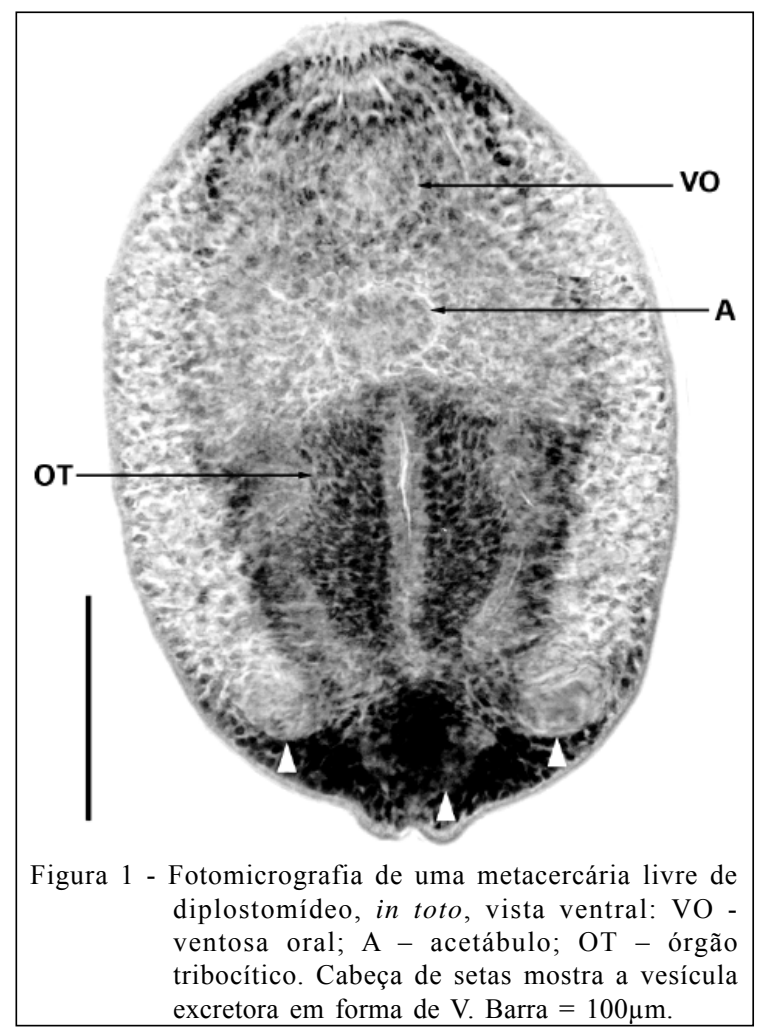

Ciência Rural, v.39, n.9, dez, 2009. 
que possibilita classificá-las em quatro tipos: "diplostomulum", "neascus", "prohemistomulum" e "tetracotyle". No tipo "diplostomulum", observa-se um sistema excretor mais simples, com três canais longitudinais (dois laterais com ramificações direcionadas posteriormente e uma mediana), conectando-se anteriormente (posterior à faringe) e posteriormente (anterior ao acetábulo), com um sistema de ramificações na parte posterior da larva, onde se encontram bolsas dilatadas, redondas ou corpos excretores ovais. As metacercárias que apresentam essas características são encontradas em três gêneros: Diplostomum von Nordmann, 1832, Neodiplostomum Railliet, 1919 e Alaria Schrank, 1788, todos são incluídos na família Diplostomidae.

Provavelmente as metacercárias coletadas nos sapinhos-de-jardim pertencem ao gênero Neodiplostomum, cujas espécies são encontradas em anfíbios, os quais desempenham o papel de segundo hospedeiro intermediário e tem aves como hospedeiro definitivo, principalmente, Falconiformes e Strigiformes. Já as espécies de Diplostomum têm peixes como segundo hospedeiro intermediário, e as espécies de Alaria possuem uma distribuição restrita à Ásia, Europa e América do Norte (NIEWIADOMSKA, 2002). Assim, fica excluída a possibilidade de as metacercárias dos sapinhos-de-jardim de Imbé, RS, pertencerem a espécies destes dois últimos gêneros. Entretanto, seria necessária uma infecção experimental para obtenção da forma adulta e assim confirmar o gênero e a espécie.

\section{AGRADECIMENTOS}

À curadora do MCT-PUCRS, Dra Gláucia Pontes. Ao professor Dr Marcos Di Bernardo (in memorian), pelas preciosas informações sobre o hospedeiro. Ao professor Dr José Felipe R. Amato, pelas discussões a respeito da identificação desse helminto. Ao IBAMA, pela licença para captura e coleta dos anuros. Ao CNPq, pela bolsa de mestrado concedida à primeira autora.

\section{REFERÊNCIAS}

ACHAVAL, F.; A. OLMOS. Anfíbios y reptiles del Uruguay. 2.ed. Montevideo: Graphis, 2003. 136p.

AMATO, S.B. et al. Metacercárias livres de diplostomídeos (Digenea, Diplostomidae) em Loricariichthys anus (Val., 1840) (Siluriformes, Loricariidae) do estado do Rio Grande do Sul, Brasil. Parasitol. día, v.25, n.1-2, 2001. Disponível em: http://www.scielo.cl/ scielo.php?pid=S071607202001000100005\&script=sci_artttext $>$ Acesso em: 06 jul. 2009. ISSN 0716-0720.

AMATO, J.F.R; AMATO S.B. Técnicas gerais para coleta e preparação de helmintos endoparasitos de aves. In: VON MATTER, S. et al. (Eds). Ornitologia e conservação: ciência aplicada, técnicas de pesquisa e levantamento. Rio de Janeiro: Editora Techinical Books, 2009. (No prelo).

DURÉ, M.E.; KEHR A.I. Explotación diferencial de los recursos tróficos en cuatro espécies de bufonidos del Nordeste Argentino. Actas Ciencia \& Técnica, v.6, p.17-20, 1999. Disponível em: http://www.unne.edu.ar/Web/cyt/cyt/biologia/b-006.pdf > Acesso em: 06 jul. 2009.

GIBSON, D.I et al. Keys to the Trematoda. London: CABI Publishing, 2002. V.1, 521p.

HUMASON, G.L. Animal tissue techniques. São Francisco: W.H. Freeman, 1972. 641p.

KWET, A.; DI-BERnARdo, M.. Pró-Mata - Anfíbios. Porto Alegre: EDIPUCRS, 1999. 107p.

NIEWIADOMSKA, A. Superfamília Diplostomoidea Poirrier, 1886. In: GIBSON, D.I. et al. (Eds.). Keys to the Trematoda. London, CABI Publishing, 2002. V.1, 521p.

YAMAGUTI, S. Synopsis of the digenetic Trematodes of vertebrates. Tokyo: Keigaku, 1971. V.1 e 2, 1074p+349 pranchas. 